\title{
Empowering Young Sex Workers for Safer Sex in Dowa and Lilongwe Districts of Malawi
}

\section{Boniface Kalanda}

United Nations Population Fund

\section{Introduction}

Selling of sex for money and other materials has increasingly become a popular means of making money and acquiring materials for young girls especially in the urban areas in Malawi ${ }^{1}$. Scores of young people are seen loitering the street corners of some hotels, casinos, bars and other places of entertainment. The young girls are also seen to frequent disco houses and patronising other places of entertainment. The girls seduce men or vice versa, they are coaxed into having quick sex in exchange for money. In a needs assessment study in Lilongwe and Dowa districts of central Malawi (FPAM, 2004), 61\% young sex workers solely depended on earnings from sex work for their living ${ }^{1}$. Worse still, these young girls are subjected to unprotected sex for various reasons which include failure to access condoms and pressure from their clients who bargain to pay more if they do not use a condom. The consequences that arise from this situation include infection with STIs including HIV, adolescent/teen age pregnancy leading to young motherhood or unsafe abortions. The majority of the young women were knowledgeable on the transmission, signs and symptoms and prevention of HIV and other STIs. The young women indicated that they were aware of the relationship between 'prostitution' and HIV and AIDS. $72.2 \%$ acknowledged to having had an unprotected sex and $21.3 \%$ indicated that they have had an STI before. Although prostitution is illegal in Malawi, it is still a popular trade among young girls because they regard it as an easy way of getting money and other materials.

In 2004 Family Planning Association of Malawi (FPAM) with financial assistance from the United Nations Population Fund (UNFPA) implemented an intervention targeting sex workers in places of entertainment by cooperating with owners of disco houses, pubs and other forms of entertainment places (proprietors), through working with the disco jockeys and some willing sex workers. The intervention project employed various IEC media to provide short but moving talks, stories and other messages that would empower and encourage the sex workers to insist on correct and consistent use of the condoms regardless of how much a client is willing to pay. The messages were also designed to encourage the young sex workers to modify their behaviour and withdraw from the practice and opt for other sources of generating income and earning a living. This study investigated the role of involving sex workers as peer educators and owners of disco houses, pubs, disco jockeys as partners in an IEC campaign to empower young sex workers to reduce STI infections including HIV.

\section{Methodology}

The intervention was implemented in Dowa and Lilongwe districts. Sensitization seminars were held with 200 sex workers where information on HIV was shared. The information was shared through presentations, group discussions and testimonies. Sex workers action groups were formed so that they could be used as contact points for the intervention.
Out of the sex workers that participated in the seminars, volunteer peer educators were identified. These peer educators were given a 6 day training (through workshop setting) where they were taught issues of HIV transmission and prevention, negotiation skills for safer sex, use of male and female condoms, rights and how to fight sex abuse, violence and exploitation, and options for income generation. A workshop for DJs, proprietors of entertainment places and representatives of sex workers was held to orient them on the initiative and seek their support.

\section{Limitations}

The number of sex workers who were initially sensitized on the intervention was lower than planned. Some sex workers were apparently afraid of being arrested. This is a legitimate fear since sex work is illegal. This intervention was however approved by the Ministry of Health through UNFPA's 5th country programme of support to Malawi.

\section{Implementation}

During the intervention, DJs inter-spaced their entertainment sessions with messages and other activities that related to sexual and reproductive health.These places were used to distribute condoms, peer educators to get in touch with other sex workers and Disco Jockeys promoted condom use and safe sex messages in between songs.

There were weekly condom and safer sex promotional events. During such events, condoms were distributed for free, special quiz sessions on HIV were held with patrons of entertainment places and awards given to those providing the best answers. The awards included calendars, t/shirts, ball bens and packs of condoms.

The intervention also established 16 dispensing sites of condoms for easy access by sex workers. These sites were toilets in entertainment places. Condoms were also distributed through peer educators in both residential areas and the places of entertainment. A sex worker Safer Sex Kit was produced and printed. This contained guidance to safer sex, negotiation skills and what to do if abused. It also contained instructions on how to correctly use both male and female condoms. Voluntary counselling and testing and STI services were offered. This was through Youth Life Centres or at Proprietors places of entertainment.

\section{Results}

Sensitization workshops were carried out and 85 sex workers were reached. There was an orientation workshop for 9 Disco Jockeys and 10 proprietors of entertainment places. 6 representatives of sex workers were also oriented.

Twenty five peer educators were recruited and trained.

3000 flyers and 200 posters containing safer sex negotiation points were produced and distributed.

Nineteen safer sex and condom promotion sessions in 19 entertainment places (bars, disco) were conducted and reached an estimated 47,000 people. Of these, 1,800 were sex workers.

Through Youth Life Centres and outreach clinics, 241 sex workers were offered VCT services. 104 sex workers were 


\section{offered STI services.}

416,038 male condoms were distributed and 60, 644 female condoms were distributed.

There were 1,028 VCT clients of whom 452 were sex workers. $87.1 \%$ of the sex workers tested HIV positive. A similar number, 452 sex workers got STI treatment. In the intervention area, 604 beneficiaries got family planning services.

The sex workers formed a women football club, Chigwirizano Night Queens and participated in a women's football league in the capital city.

Through this intervention, other interested parties gave assistance to some sex workers to leave the sex trade. 6 sex workers were trained in tailoring and they have since established small scale businesses.

\section{Discussion}

Since the advent of HIV and AIDS, it has been recognized that clients of sex workers can be bridging populations between the sex workers and the general population ${ }^{2}$ This has made it imperative to introduce HIV prevention interventions in sex workers.

This has been difficult due to issues around stigmatizing such populations ${ }^{3}$. Recently, UNAIDS published a Guide Note (2007) whose content groups of sex workers protested at the 2008 International AIDS Conference in Mexico city, Mexico ${ }^{4}$

In this intervention, an appropriate rapport was established with a community of sex workers.

There was trust between the sex workers and the project staff. This is one of the few interventions that has managed to do this successfully. During the intervention, there was an increase in sex workers knowledge on HIV and AIDS and other SRHR issues. There was also an increase in the capacity of sex workers to address HIV and AIDS and other SRHR issues affecting them and their fellow sex workers. Peer educators managed to disseminate information to empower sex workers on safer sex negotiation and demonstrate to fellow sex workers how to use and dispose off condoms correctly. Those with STIs were encouraged to seek medical treatment in time. This shows that sex workers have got a role to play in the fight against HIV and AIDS. Sex workers have an interest and are willing to play this role if they are supported and protected. The use of sex worker peer educators has proven to be an effective way to reach out to fellow sex workers with HIV and AIDS and other SRHR related messages.

In this intervention, Disco Jockeys and Proprietors of entertainment places have also proven to be valuable partners in the fight against HIV and AIDS. DJs can play an instrumental role in disseminating HIV and AIDS prevention messages especially to sex workers and their clients who spend some of their free time in pubs and other entertainment places.

\section{Conclusion}

This intervention has demonstrated that sex workers, disco jockeys and proprietors of pubs and other entertainment places have a role to play in the fight against HIV and AIDS. Sex workers are willing to participate in prevention programmes and to be peer educators. Disco Jockeys and
Proprietors can allow their places to be used as points for disseminating prevention messages and proving care and support including VCT. Governments, even where sex work is not illegal, should work with its partners to provide for HIV and AIDS services to sex workers as with other vulnerable populations.

\section{Acknowledgements}

I would like to acknowledge the financial and technical support provided by UNFPA and FPAM to carry out the intervention. In particular I would like to thank the efforts of Esperance Fundira and Anna Chinombo at UNFPA and Effie Perekamoyo, Mathias Chatuluka, Temwa Munkhuwa and Bessie Nkhwazi at FPAM in making the intervention a possibility.

\section{References}

1.FPAM (2004). Needs Assessment on reaching out to young women involved in sex workers through social gatherings and dance places. Family Planning Association of Malawi, Lilongwe, Malawi.

2.Hesketh, T., Zhang, J., Qiang, D.J.. HIV knowledge and risk behaviour of female sex workers in Yunnan Province, China: potential as bridging groups to the general population. AIDS Care; 200517(8): 958-66

3.Scambler, G., Paoli, F. Health work, female sex workers and HIV/ AIDS: global and local dimensions of stigma and deviance as barriers to effective interventions. Social Science Medicine;(2008) 66(8):184862.

4.UNAIDS, UNAIDS guidance note: HIV and Sex work, 2007. UNAIDS, Geneva. 